\title{
BRINCADEIRA, CORPO E MOVIMENTO: RELATOS DE PESQUISAS SOBRE O USO DAS ÁREAS EXTERNAS NA EDUCAÇÃO INFANTIL
}

Rogério Correia da Silva ${ }^{\mathrm{i}}$ Celiane Oliveira dos Santos ${ }^{\text {ii }}$

\begin{abstract}
Resumo: O artigo pretende discutir dados de duas pesquisas realizadas em diferentes capitais brasileiras - Fortaleza e Belo Horizonte - que abordaram o uso das áreas externas e o brincar em escolas de Educação Infantil. As investigações são de natureza qualitativa e tiveram as crianças como principais sujeitos das pesquisas, combinando diferentes procedimentos metodológicos para a construção dos dados. As análises mostraram a desvalorização no uso dos espaços externos pelas escolas em contraste com os desejos e necessidades das crianças. Posturas adultocêntricas por parte das professoras foram reveladas nas imposições de brincadeiras às crianças, nas tentativas de regulação dos corpos, espaços e materiais disponíveis nas áreas externas das instituições.
\end{abstract}

Palavras-chave: Espaços externos; Brincar; Educação Infantil; Movimento.

\section{CHILDREN'S PLAY, BODY AND MOVEMENT: REPORTS OF RESEARCH STUDIES RELATED TO THE USING OF PLAYGROUNDS IN EARLY CHILDHOOD EDUCATION CENTERS}

\begin{abstract}
This paper aims do discuss data produced by two investigation studies in different Brazilian capitals - Fortaleza and Belo Horizonte - which explored the use of playgroundspaces as well as playing itself in Early Childhood Education schools. A qualitative approach with different procedures for the construcion os the data was utilized in the two studies which had children as the main subjects. The analysis of the data showed that the schools don't attribute much value to the playground spaces in contrast to to children's needs and desires. The results also showed the teachers had adult oriented attiudes which resulted in lack of respect related to children 's choosing their own playing, in attempts to regulate children' bodies as well the kinds of materials available in the school' playground spaces.
\end{abstract}

Keywords: Playground spaces; Playing; Early Childhood Education; Movement.

\section{Introdução}

No contexto da Educação Infantil, várias pesquisas têm registrado o interesse das crianças pelas experiências vivenciadas nas áreas externas, em oposição à sala de atividades. É evidente o interesse dos meninos e meninas pelas interações e brincadeiras desenvolvidas nesses espaços. Nessa perspectiva, esse trabalho objetiva discutir dados de duas pesquisas 


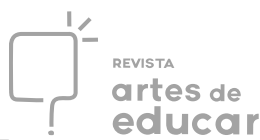

(SANTOS, 2015; SILVA, ZOBERI E SINTOBI, 2016) realizadas em diferentes capitais brasileiras - Fortaleza e Belo Horizonte -, que abordaram o uso das áreas externas em escolas municipais de Educação Infantil.

Destacamosaquia importância dada ao estudo sobre o uso das áreas externas nas instituições de Educação Infantil o que, por sua vez, suscita também algumas preocupações. Primeiramente, por ser o local preferido das criançascomo mostram várias pesquisas.Na investigação realizada por Silveira (2004), que utilizou a produção de imagens pelas próprias crianças sobre a escola de Educação Infantil, a área externa foi fotografada por quase todas elas. Esse era o local de que mais gostavam, voltado para o brincar e a diversão, sendo considerado o "prêmio" que recebiam quando faziam "tudo certo". Os estudos de Araújo (2008) corroboram a predileção das crianças pelas áreas externas, pois ao desenharem a escola, as crianças evidenciaram a opção pelos espaços externos, em detrimento dos espaços internos (salas). Na Consulta sobre Qualidade da Educação Infantil (CAMPOS; CRUZ, 2006), as falas das crianças revelaram a necessidade que elas sentem de estarem no espaço externo e o valor atribuído aos brinquedos e brincadeiras que acontecem fora da sala de referência da turma.

Apesar do evidente interesse das crianças pelas áreas externas, Horn (2013) ressalta que, de todos os espaços de uma instituição de Educação Infantil, os espaços externossão os quemerecem especial atenção, dado o uso desqualificado que deles se temfeito por este país. Além de reduzidos em relação às outras construções e do seu pouco uso, a pesquisadoraconstatou outros problemas:

- o distanciamento dos elementos da natureza-poucas árvores, pisos cimentados, ausência de elementos como areia, água, terra-importantes elementos para a educação sensorial da criança;

- pouca flexibilidade e adaptação dos espaços externos para acompanhar as grandes variações climáticas da região;

- pouca presença de aparelhos como brinquedos de grande porte e bancos (quando estão presentes, falta manutenção);

- pouca apropriação de alguns espaços pelos professores, pois foram considerados perigosos por envolver risco de acidentes; 


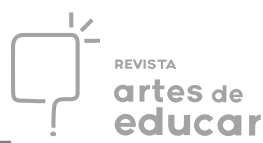

- a identidade de uma escola infantil atrelada a um modelo tradicional como local de "ensino", pouco pensando em propostas de uma pedagogia participativa.

O documento Diretrizes Básicas de Infraestrutura para Funcionamento das Instituições de Educação Infantil (BRASIL,2006) estabelece que as áreas livres devem corresponder a cerca de $2 / 3$ da área total do terreno, podendo reduzirno máximo a 50\%. Todavia, mesmo que isso fosse uma realidade (o que de fato não é) para a maioria das instituições de Educação Infantil no país, resta-nos ainda o desafio do "emparedamento das crianças",como afirma Léa Tiriba (2008),ao concluirque o planejamento do espaço escolar, orientando-se pela cobertura do atendimento (sem pensar na qualidade dos serviços prestados), pela garantia do processo de aprendizagem através do controle da atenção e da limitação dos movimentos da criança, traz como consequência uma proposta que despotencializa a curiosidade da criança, afasta-a do contato com a natureza e ignora a importância do convívio social.

Como referencial teórico, destacamos os estudos que tratam da relevância da organização dos espaços e ambientes na Educação Infantil (FORNEIRO, 1998;HADDAD \& HORN, 2011). O espaço na Educação Infantil é visto aqui como elemento curricular, parte integrante da ação pedagógica, esteticamente pensado e organizado para sugerir formas de interação e aprendizagem, que tanto acolha como desperte o interesse das crianças reconhecendosuas necessidades e possibilitando o desenvolvimento de suas potencialidades. Neste sentido, o espaço é também um reflexo das concepções pedagógicas que norteiam o trabalho educativo nas creches e pré-escolas.

Assim sendo, serão apresentados dados das pesquisas deSantos (2015)eSilva, Zoberie Sintobi(2016)que trazem reflexões e problematizações sobre o brincardas crianças na Educação Infantil e o uso de áreas externas. No primeiro estudo,recorte de uma pesquisa de mestrado,o objetivo central foi analisar as concepções das crianças, professora ecoordenadora pedagógica sobre o recreio como atividade da rotina em uma escola pública de Educação Infantil na cidade de Fortaleza/CE. Na segunda pesquisa,desenvolvida no âmbito do Programa Institucional de Bolsa de Iniciação Científica (PIBIC), buscou-se investigar as mudanças nos processos de socialização e no brincar das crianças decorrentes da reestruturação de espaços e criação de ambientes em uma Unidade Municipal de Educação Infantil (UMEI), localizada na cidade de Belo Horizonte/ MG. Visou também a elaboração e 


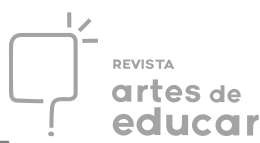

o desenvolvimento de projetos que refletissem melhor as expectativas e anseios do público atendido. Ao final, trazemos alguns apontamentos acerca do direito ao brincar, ao movimento e a ressignificação das áreas externas nas propostas pedagógicas das escolas de Educação Infantil.

\section{Percursos Metodológicos}

As duas investigações são de natureza qualitativa e tiveram as crianças comoprincipaissujeitos das pesquisas, combinando diferentes procedimentos metodológicos para a construção dos dados.No estudo de Santos (2015),enfatizaremoso uso da observação $\begin{array}{llllll}\text { participante } & \text { e } & \text { dos } & \text { desenhos } & \text { estórias } & \text { (D-E) }\end{array}$ ${ }^{3}$ produzidos pelas crianças entrevistadas.O diário de campo, fotografia e filmagem foram as formas de registros empregadas. Participaram do estudo oito crianças na faixa etária de cinco anos de idade (quatro meninas e quatro meninos).

Na pesquisa de Silva, Zoberi e Sintobi(2016)caracterizada como uma pesquisa-ação, a proposta foi estabelecer ações conjuntas com o grupo de professores e direção da escola a fim de diagnosticar e propor mudanças aos problemas identificados. Participaram do trabalho todos os professores da escola, a direção, os pais e algumas turmas de crianças.Foram utilizadas entrevistas com passeios, desenhos, observação participante, fichas, fotos e croquis. Daremos ênfase neste artigoà apresentação das fichas de observação das brincadeiras das crianças no parque de brinquedos e ao estudo dos desenhos das crianças.

Apresentaremos o trabalho desenvolvido com uma turma de crianças de cinco anos (25 crianças) da UMEI São João. Realizamos entrevistas mediadas pela produção de desenhos. Inspiramo-nosna pesquisa deMartinseGaranhani(2011) sobre a organização do espaço na Educação Infantil na perspectiva das crianças.Nesse sentido, tivemos a intenção de articular a entrevista, o desenho e o deslocamento pelos espaços da UMEI sob a orientação das crianças.

No primeiro estudo (SANTOS, 2015),cada criança realizouquatro desenhos com estórias (D-E)subdivididos em: dois D-E positivos a partir da solicitação "desenhe uma criança da sua idade num recreio bem legal" e dois D-Enegativos a partir da solicitação "desenhe uma criança da sua idade num recreio que não é legal". Além da quantidade de desenhos solicitada, outra adaptação da técnica consistiu no fato de o desenho não ser 
totalmente livre, pois a criança era solicitada a desenhar uma criança da idade dela em situações diferenciadas de recreio e em seguida, criar uma história oral baseada nessa produção.

É oportuno salientar que os desenhos e estórias produzidas pelas crianças visaram possibilitar um maior aprofundamento acerca dos significados atribuídos pelos sujeitos ao fenômeno focalizado na pesquisa. Nesse sentido, em momento algum da investigação foi lançado um olhar avaliativo sobre as produções das crianças. Assim como nos estudos de Andrade (2007), tanto os desenhos como as estórias foram considerados formas de expressão e não instrumentos de classificação e/ou diagnóstico das crianças.

No segundo estudo (SILVA, ZOBERI E SINTOBI, 2016), o foco recaiu sobre a percepção das criançascom relação àprópria escola de Educação infantil, sobre seu brincar, utilizando paraisso os desenhos infantiseuma ficha de observaçãopara registro das brincadeiras que aconteceram no parquinho.

Seguindo as orientações de Gobbi(2014), buscamos um olhar mais atento sobre os desenhos das crianças da turma de cinco anos da UMEI. Nosso objetivo principal foi captar as suas narrativas, os sentidos e significados que dão aos espaços da escola. Tratamos aqui o desenho como uma produção cultural da criança, uma forma de representação social e, nesse sentido, expressão cultural de um grupo infantil. Como mesmo nos fala a autora:

É interessante que consideremos a comunicação com o grupo social nos quais as crianças estão inseridas, observando que para a criança pequena, em diferentes ambientes por ela frequentados, desenhos e outras formas expressivas não estão separados do cotidiano, ao contrário, podem estar espalhados ou esparramados sucedendo todos os dias. Seus trabalhos resultam de pesquisa pessoal, da interação com outras crianças e com o entorno social e cultural ao qual estão expostas e que ao mesmo tempo constroem. Suas criações são registros, marcas históricas deixadas por elas desde pequeninas. Sintetizam e derivam de preocupações culturais, valores estéticos, modos de ver e estar no mundo. Esses desenhos e seus desenhistas procuram, sem dúvida, por vezes corresponder às demandas sociais que lhes interrogam e impõe jeitos de criar seus desenhos e de constituir-se frente ao mundo" (GOBBI, 2014, p. 156).

Buscamos identificar em seus desenhos as marcantes e inventivas maneiras como as crianças expõem os diferentes assuntos de seu interesse e, assim, documentam o seu cotidiano. Para Gobbi (2014),ao desenhar, as crianças articulam num mesmo movimento os atos de ver, apropriar e elaborar, materializando aquilo que é visto com todos os sentidos. 


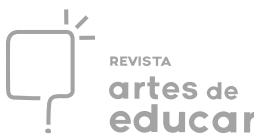

Em relação às brincadeiras das crianças nos espaços externos fizemos uso da obervação baseada na "ficha de mapeamento centrado no lugar" (CORDAZZO, et ali, 2008; KUHNEN \& RAYMUNDO, 2011). Definimos 13 categorias para classificação dos comportamentos das crianças ${ }^{4}$. A cada 5 minutos, cada setor era observado, e nesse momento, eram quantificados o número de meninos e meninas presentes e o tipo de comportamento que desempenhavam. As fichas de observação identificavam também as idades das turmas e a quantidade total de crianças que frequentavam o parquinho durante o período de observação. Foi-se aplicado um pré-teste para ajustes e treinamento dos pesquisadores envolvidos na coleta dos dados. Foram realizadas cerca de 20 observações de cada setor.

\section{Resultados e Discussão}

A escola da rede pública de ensino do município de Fortalezaonde foi realizado o primeiro estudofica situada em um bairro comercial e educa crianças na faixa etária de três a sete anos,em sua maioria filhos (as) de comerciários ede famílias de baixa renda residentesnos bairros próximos. A escola possui 12 salas de atividades com banheiros internos, um laboratório de informática, uma biblioteca, uma sala para os professores com banheiro interno, uma sala para diretoria, outra sala para a secretaria, um pátio coberto, um parque infantil (área externa), um almoxarifado, um depósito, uma dispensa e um refeitório.

A área ao ar livre apresentava um espaço amplo, algumas árvores de médio porte e equipamentos de parque, como: caixa de areia, escorregador, balanço, trepa - trepa e gangorra. A maior parte da área de parque era revestida com piso de pedra. Nesse espaço, onde acontecia o recreio diariamente, as crianças realizavam diversas brincadeiras e brincar de pega-pega era a principal delas. A figura, a seguir, mostra a planta baixa da escola investigada. 
Figura 1 - Planta baixa da escola

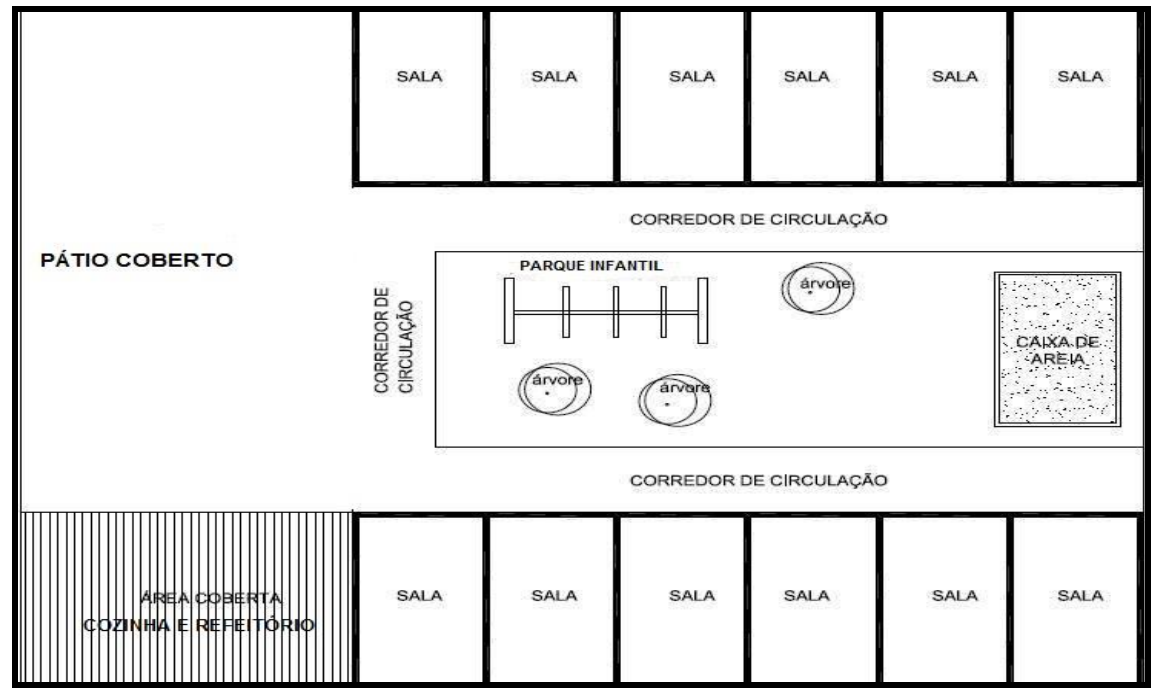

Fonte: Arquivo de pesquisa

A área externa da referida escola era utilizada todos os dias pelas crianças da préescola, por ocasião do recreio que tinha duração de vinte minutos. Durante esse tempo, as crianças não contavam com materiais ou brinquedos para as suas brincadeiras, como: cordas, bambolês, jogos de encaixe, baldes de areia, pás, garrafas, observando-se apenas a disponibilidade de bolas para o jogo de futebol no pátio coberto. Devido à falta de brinquedos e materiais, muitas vezes as crianças coletavam nas lixeiras da escola, restos de embalagens dos alimentos consumidos na hora do lanche, para serem utilizadas nas brincadeiras, como pode ser observado na fotografia 1.

Além da ausência de brinquedos e materiais, muitos equipamentos do parque infantil estavam quebrados (fotografia 2). Foi possível observar, em vários momentos, as crianças maiores tentarem, sem sucesso, consertar o balanço ou gangorra que estavam com as cordas quebradas. A falta de manutenção nesses equipamentos oferece muitos riscos de acidentes às crianças, que os escolhiam para brincar.É importante ressaltar que os espaços escolares nunca são neutros (FORNEIRO, 1998); suas formas de organização e utilização também revelam as concepções de infância, criança e educação infantil que balizam as práticas pedagógicas na instituição. 


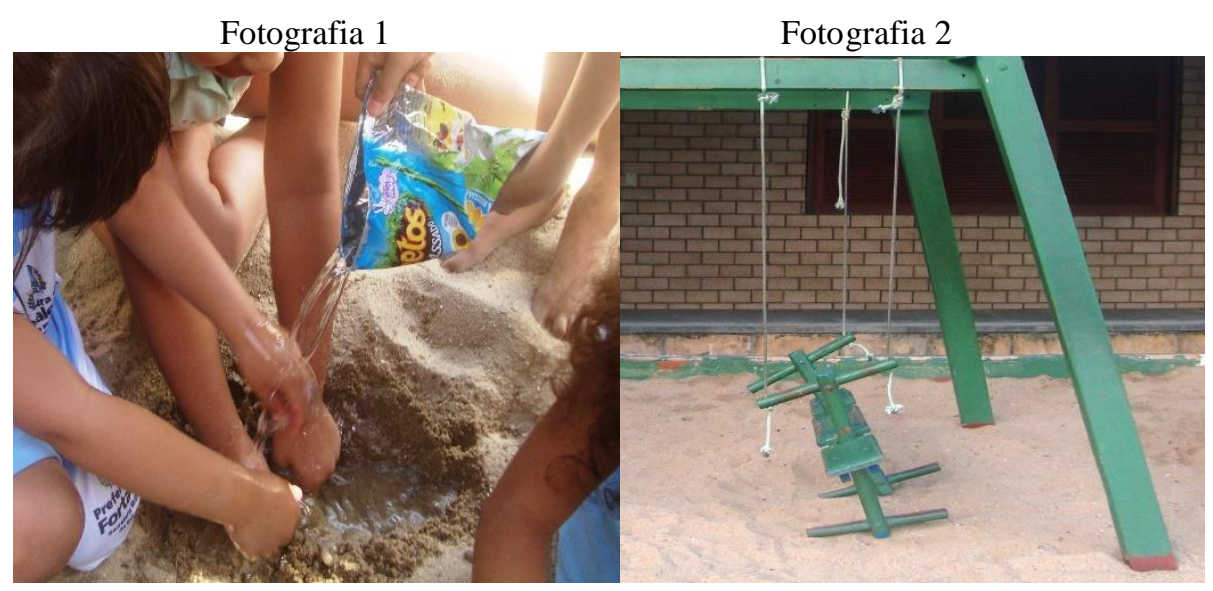

Fonte: Arquivo de pesquisa. Fonte: Arquivo de pesquisa

É interessante destacar que, apesar de ser uma área relativamente ampla, o espaço externo, onde acontece o recreio, parecia se reduzir quando se constatava o número de crianças que o frequentava: em média 130 crianças, provenientes das turmas Infantil $\mathrm{V}, 1^{\circ} \mathrm{e}$ $2^{\circ}$ anos. Durante o período de observação, constatou-se que apenas um ou dois adultos permaneciam com as crianças nesse espaço, geralmente as funcionárias ligadas ao trabalho desenvolvido na cozinha e/ou serviços gerais.

$\mathrm{O}$ corpo docente, durante a atividade do recreio, dirigia-se à sala dos professores. Era comum alguma criança bater à porta da sala dos professores para se queixar de acontecimentos ocorridos no recreio - conflitos, acidentes, violência física - e solicitar a ajuda de algum deles e quase sempre não eram atendidas. $O$ contexto observado revela a falta de valorização das atividades ocorridas nas áreas externas, pois as crianças não contavam com a mínima infraestrutura e acompanhamento pedagógico.A ausência de acompanhamento pedagógico durante as atividades ocorridas nas áreas externas demonstra a desvalorização das brincadeiras e a desconsideração da dimensão pedagógica desses espaços, pela equipe de profissionais da escola. Para Richter e Vaz(2010, p. 675):

Apesar de esses períodos de parque aparecerem declarados como "ocasiões privilegiadas de educação", tanto os discursos dos professores quanto as suas ações distinguem esses momentos dos demais, estabelecendo uma espécie de contraposição entre "tempo de trabalho" e "tempo livre". Nessa relação, os momentos de parque, além de se configurarem como períodos de renovação das energias para as demais atividades, acabam por dispensar a exigência de um acompanhamento mais cauteloso por parte dos professores. Nesses termos, o olhar adulto poderá apenas, afastar as crianças de locais inconvenientes ou evitar feridas "expostas". A ausência de uma aproximação mais cuidadosa acaba por deixar as crianças entregues à ambiguidade do 
"espontâneo", expostas ao risco da violência que se materializa e permanece em marcas que se colocam, principalmente, sobre o corpo (grifos dos autores).

Kishimoto (2001) considera que as brincadeiras "livres", em muitos casos, são vistas pelos professores como descanso de atividades dirigidas realizadas na sala e não como forma de socialização e integração das crianças. Essa compreensão torna difícil justificá-las como parte do projeto pedagógico da escola. Desse modo, segundo a autora, "para os professores o parque serve para descansar e brincar e a sala de atividades para estudar e trabalhar, define-se então a função da Educação Infantil: estudar” (p. 238).Por conseguinte, esse modo de pensar a educação e o cuidado não atende aos interesses e necessidades infantis, ocasionando prejuízos às crianças que frequentam esses espaços.

As crianças expressaram de maneira muito clara a necessidade que sentem e o valor que atribuem às brincadeiras nas áreas externas.Na opinião delas:não é legal não ter nada pra gente brincar. A estória criada por Natanae ${ }^{5}$ durante a entrevista individual (D-E) mostra que a existência de brinquedos no recreio é imprescindível para que a experiência na escola seja significativa:

Pesquisadora: Natanael, agora conta uma história sobre o teu desenho?Natanael: Uma escola aqui, aí tinha um menino, e aí ele gostava muito do recreio, aí ele ficava até acabava o recreio e ele não ia pra sala. Ele era novato e tinha acabado de chegar, ele pensou que essa escola era muito legal, mas não tinha nenhum brinquedo, aí ele ficou chorando.... (NATANAEL 1/2 D-E $2^{\mathrm{a}}$ etapa). 


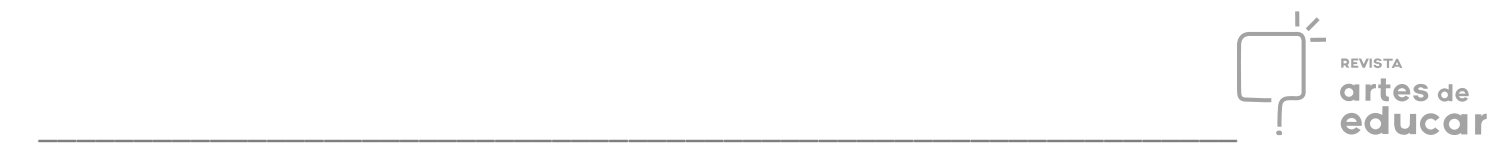

Figura 2 - Desenho com Estória

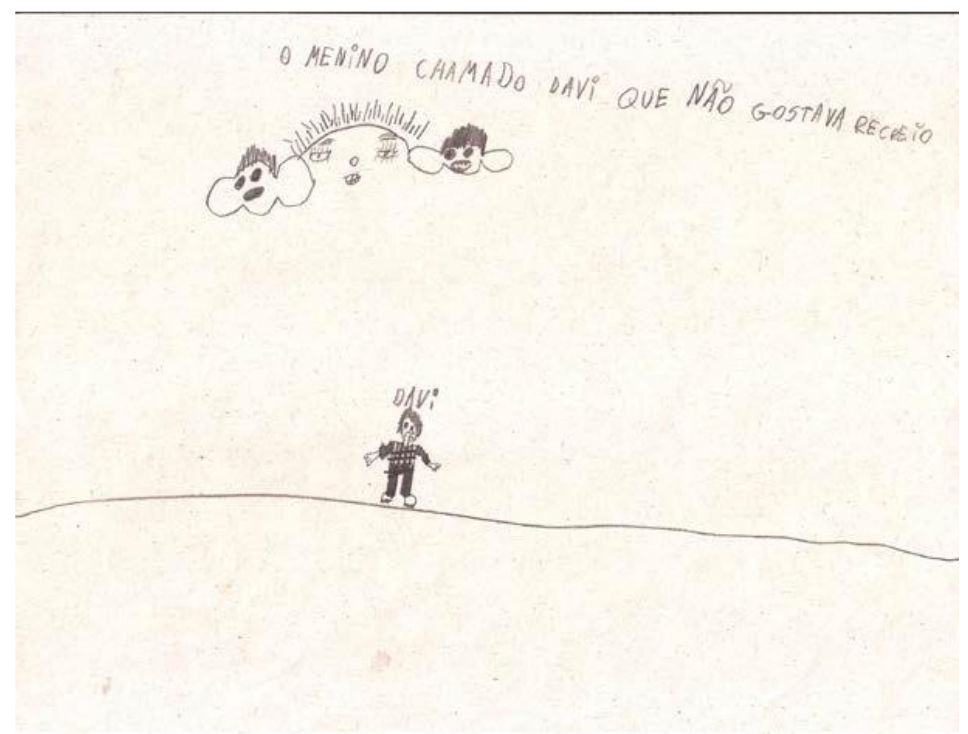

Fonte: Arquivos da pesquisa

As crianças revelaram que o sentido da existência do tempo na área externa - recreio - está relacionado com a possibilidade de brincar, oportunidade que tem ainda mais valor pelo fato de que na sala não são permitidas as brincadeiras, conforme o diálogo a seguir:

Danilo: $\mathrm{O}$ menino quer brincar com ele, mas não pode.... [tenta escrever as palavras N-Ã-O E-S-T-E-J-A] (refere-se à ideia de não esteja brincando)

Pesquisadora: Mas onde esses meninos estão brincando?

Danilo: Na sala, e não pode!

Danilo: No recreio, no recreio que pode!

Pesquisadora: Só no recreio?

Danilo: É.

Pesquisadora: E o que eles podem fazer na sala?

Danilo: Pode fazer desenhar, pode fazer brincar um pouquinho, pode fazer estudar, pode fazer ler, pode fazer...escrever... o que mais... jogar bila até que pode na sala, mas só um pouquinho, muito não né, porque a tia pode chamar a mãe e reclamar, né.

(DANILO, 2/2 D-E $1^{\circ}$ etapa).

A necessidade que as crianças sentem de brincar e o valor atribuído aos amigos nas brincadeiras também apareceram nas falas das crianças que participaram da pesquisa desenvolvida por Silva (2010) em um Jardim de Infância português. A referida autora verificou que as crianças não dispõem de tempo suficiente para a brincadeira livre, sobretudo no Jardim de Infância, e que o seu tempo está ocupado com atividades pedagógicas e é 


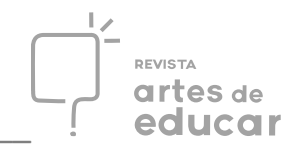

controlado e condicionado por decisões dos adultos, negando à criança o seu direito de participante ativo na gestão do seu próprio tempo, ritmos e corpos.

\section{Brincar no parquinho da UMEI São João: problemas e soluções}

A UMEI São João estava localizada na Vila Fátima. Incrustrada no paredão da Serra do Curral Del Rey, era parte integrante do Aglomerado da Serra, o maior conjunto de favelas de Belo Horizonte, com cerca de 50 mil pessoas.

Figura 3 - Desenho da UMEI São João

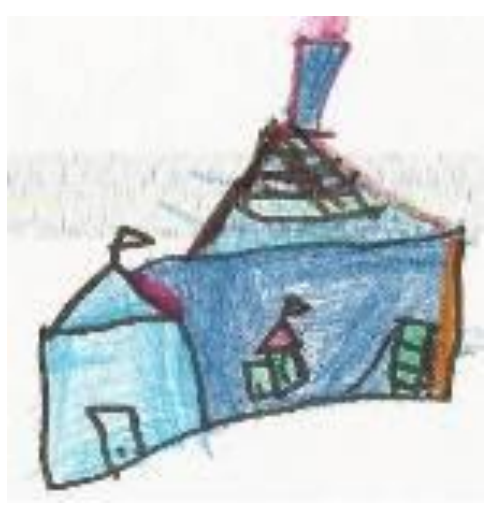

Fonte: arquivos da pesquisa

Figura 4 - Foto satélite da UMEI São João

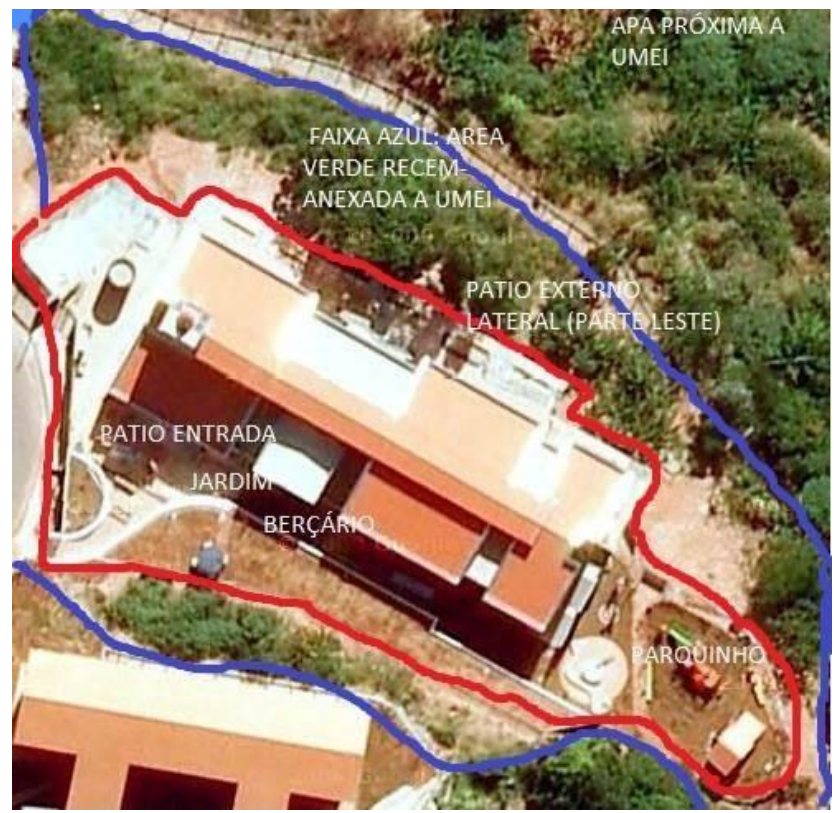

Fonte: arquivos da pesquisa

Revista Interinstitucional Artes de Educar. Rio de Janeiro, V. 6, N.1- pág. 53-71 janeiro-abril de 2020:

"Educação: Corpo em movimento II." - DOI: 10.12957/riae.2020.45820 


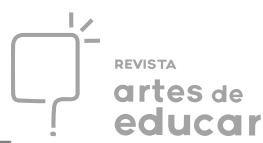

A UMEI São João foi construída em um pequeno terreno com forte declive. O prédio possuía dois andares ofertando ao todo 15 turmas de Educação Infantil, do berçário aos cinco anos. Atendia diariamente cerca de 240 crianças em horários parciais e integral. Cerca de apenas $20 \%$ do terreno era constituído pelas áreas livres externas. Dos espaços externos disponíveis às crianças (corredores, solário, mini-arena), o parquinho era a maior área livre disponível, medindo cerca de $150 \mathrm{~m}^{2}$.

Analisando os desenhos das crianças, pudemos perceber que a UMEI foi muitas vezes representada através do desenho do seu prédio. Na maior parte dos desenhos, as crianças deram destaque à representação da fachada da entrada, onde estão presentes a torre, o telhado em formato triangular, as janelas gradeadas e a forte cor vermelha.

Tratando ainda dos elementos arquitetônicos, encontramos nos registros das crianças a presença de elementos que representam divisão/separação/ isolamento ou cerceamento dos espaços. Isto fica presente através da presença de grades, estivessem elas nas janelasou cercas, ou simplesmente as portas (sempre fechadas). Uma das imagens em que ficou muito fortea ideia do confinamento e da separação foi feita por Ana Luísa, que desenhou ao uma criança e um quadrado com grade (figura abaixo):

Figura 5-Desenho da UMEI

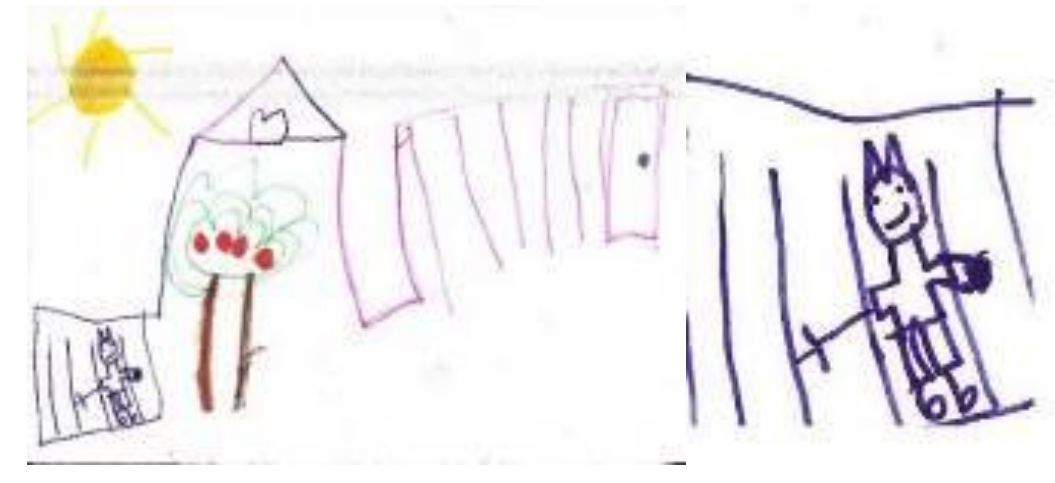

Fonte: arquivos da pesquisa

Os brinquedos, sobretudo os de grande porte, foram muito representados nos desenhos das crianças. A piscina de bolinhas, o pula-pula e o escorregador estão muito presentes em seus desenhos. Um brinquedo se destacou dos demais não somente por sua recorrência, mas também pelas diversas maneiras criativas como foi representado. Trata-se do brinquedo de grande porte chamado carinhosamente pelas crianças de Castelo. Ele era constituído por torres 


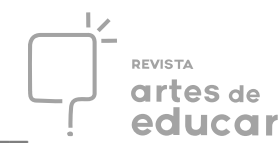

de observação, escorregador e escadas. A forte presença dos brinquedos nos desenhos das criançassugere que ao serem perguntadas sobre o que consideram mais significativo na UMEI,elas deram destaque às brincadeiras, a partir das estruturas construídas voltadas para o brincar.

Pelo que podemos perceber pelos desenhos, a maioria deu muita ênfase aos espaços externos da UMEI. É lá que encontramos os brinquedos de grande porte e onde as crianças realizavam as suas brincadeiras. Quando representavam os espaços internos faziam questão de incluir neles os brinquedos de grande porte que lá existiam como piscina de bolinha e pulapula. Se a leitura dos desenhos é marcada tanto pelo que diz quanto pelo que não diz, sentimos falta de outros espaços que ganharam pouco destaque nos desenhos das crianças, como a sala de atividades, a brinquedoteca ou mesmo outras atividades realizadas pelas crianças, como a leitura de livros, atividades de desenho e escrita. Poucos desenhos fizeram referência a momentos da rotina diferente do brincar.

Figura 6 - Desenho representando crianças brincando no parquinho

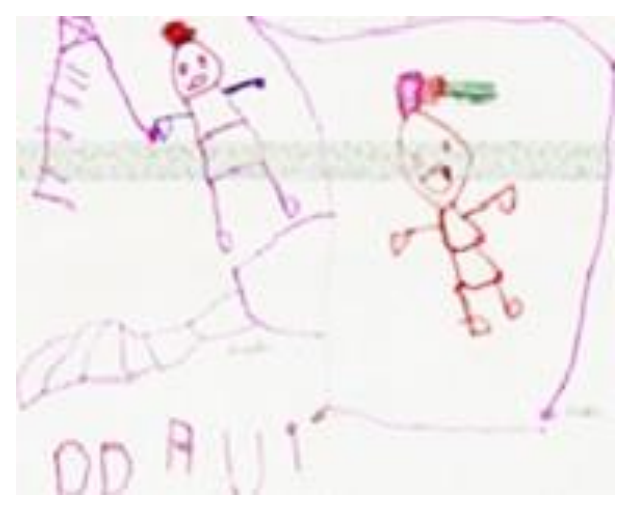

Fonte: arquivos da pesquisa

O parque de brinquedos funcionavanos fundos da UMEI com a presença de vários aparelhos,como podemos ver no croqui abaixo (figura 7): escorregador(S2), casinha(S1), castelo(S5), cavalos de madeira,túneis e árvore(S3), uma pista de corrida, uma mesa e bancos de alvenaria(S4 e S6). Frequentavam o parque diariamente por cerca de 30 minutos as crianças de um a cinco anos de idade. As crianças do berçário raramente frequentavam o parquinho porque suas professoras preferiam o usodo solário. O parque não possuía qualquer área coberta que não fosse dos próprios brinquedos. Todo o parque recebia sol durante todo o dia, todavia na parte da tarde o prédio da UMEI projetava uma sombra bastante generosa, além da produzida pela única árvore presente no espaço. 


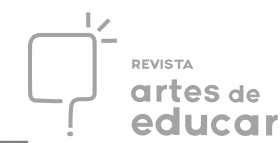

Esse espaço, considerado pelas professoras da UMEI como o principal local voltado para o brincar, apresentava vários problemas a serem resolvidos, dentre os quais, podemos citar dois como exemplos: os conflitos e brigas entre crianças e a falta de brinquedos mais adequados às crianças de um a três anos.

Para a primeira questão, a coordenação pedagógica havia reduzido o número de turmas que utilizavam simultaneamente o espaço (de 2 turmas para 1) como forma de diminuir os conflitos entre as crianças, acreditando que o principal motivo era a disputa pelo uso dos brinquedos. Para a segunda questão, a escola adquiriu um novo brinquedo mais adequado ao tamanho das crianças bem pequenas; um castelo com rampas, decks e túneis e escorregadores (setor 5). Os resultados das observações indicaram que a maioria dos setores, sobretudo aqueles com presença de brinquedos, apresentaram uma boa ocupação pelas crianças durante suas brincadeiras. Todavia, as crianças de um e dois anos continuaram utilizando mais o brinquedo do setor 2 do que propriamente aquele que havia sido montado para uso delas(setor 5).

Em nossas hipóteses, concluímos que a não ocupação do castelo pelas crianças menores se devia ao local onde foi instalado (isolado do circuito) e aouso diferenciado que crianças pequenas e maiores faziam do espaço, do maior ou menor grau de autonomia que possuíam. As crianças menores permaneciam nos brinquedos em que suas professoras estavam próximas, enquanto as crianças maiores não tinham o adulto como uma referência necessária para suas brincadeiras. Concluímos, então, que a circulação das professoras pelos brinquedos também afetava a sua ocupação pelas crianças (CAMPOS,2003). 


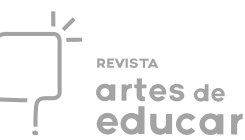

Figura 7-Croqui da área do parquinho

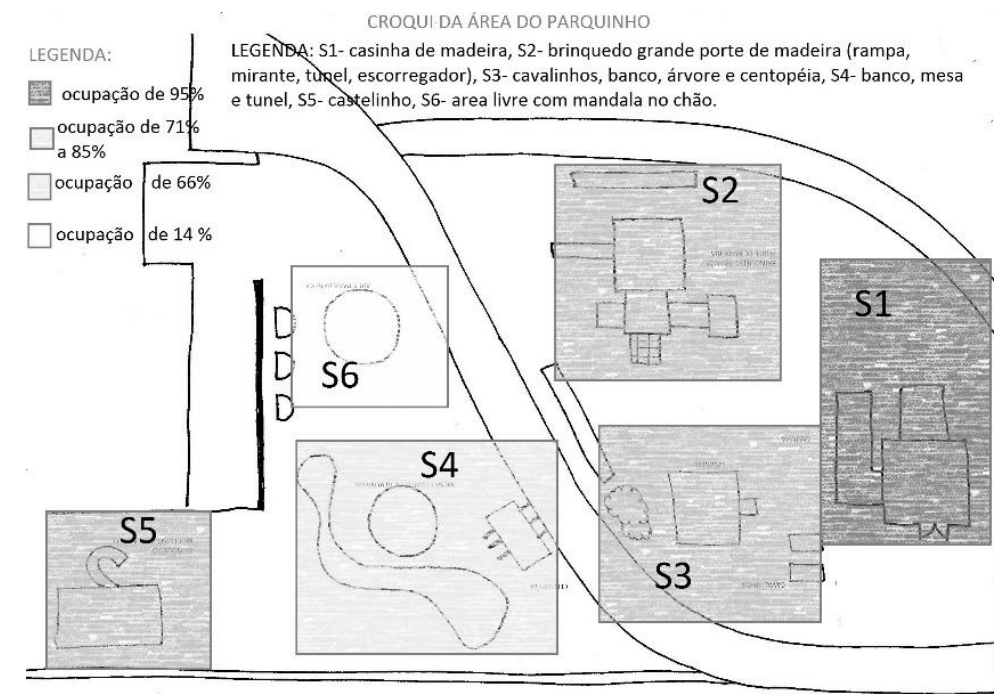

Quanto à forma de interação das crianças durante as brincadeiras no parquinho, verificamos que a forma associativa foi a que mais predominou. A casinha, o castelo e o brinquedo de madeira foram os locais mais escolhidos para brincadeiras associativas. Chamamos a atenção para o comportamento solitário que foi o segundo tipo de comportamento mais observado nas brincadeiras das crianças nos brinquedos. O Setor 5 onde ficava o castelo foi ao mesmo tempo o local mais procurado pelas crianças tanto para brincadeiras associativas quanto para os momentos em que buscavam um certo isolamento dos colegas e da professora. Em relação ao tipo de brincadeiras realizadas pelas crianças no parquinho, predominou as de faz de conta sobre as de construção e a de regras.

No registro das brincadeiras de faz de conta cabe ressaltar o impacto que os brinquedos tinham sobre as brincadeiras das crianças ao propor temas. Foi o caso do setor $1-$ casinha - que concentrou o maior número de brincadeiras de faz de conta. Nos nossos registros, pudemos identificar que as brincadeiras das crianças se adequavam ao ambiente proposto pelo espaço. Chamou-nos a atenção a demanda das crianças por brincadeiras de construção. Apesar de não haver nenhum material no parquinho voltado para este tipo de atividade, as crianças descobriam maneiras diferentes de incorporar ações como coletar folhas e capim ou mesmo fazer tentativas de desmontar (sob o olhar vigilante das professoras) as rampas do escorregador do castelo. Associada a muitos momentos em que as crianças foram vistas explorando o espaço, percebemos que uma lacuna a preencher no parquinho seria 


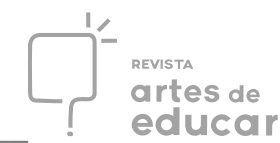

voltada para promover este contato maior das crianças com a natureza e com situações e materiais que pudessem dar suporte às suas brincadeiras, de construção e exploração do ambiente, timidamente executadas, dada a pouca materialidade disponível.

\section{Considerações finais}

As duas experiências analisadas exemplificam modos diferentes (e muitas vezes contrastantes) das escolas e profissionais da educação infantil se posicionarem diante do uso das áreas externas. Por sua vez, as duas propostas atribuem sentidos diferentes ao brincar das crianças. Enquanto na primeira experiência a escola organiza o brincar "livre" das criançasem um curto espaço de tempo denominado de recreio - que se confunde com tempo de descanso da professora -, a segunda experiência analisa o brincar como momento pedagógico; conta com a presença das professoras e há a demonstração de intencionalidade no uso do parquinho e dos brinquedos, por cada turma da instituição.

No primeiro caso, o que poderia se configurar como uma oportunidade rica de trocas de experiências entre crianças de diferentes idades (em contraste com a segunda) acaba se tornando em momento de conflito e disputa. Por outro lado, aquilo que poderia ser lido como um empobrecimento da experiência das crianças (uma turma por vez), acaba, no entanto, garantindo o acesso das crianças aos brinquedos, mesmo que sob o risco de não estimular potencialmente as interações no grupo.

Percebe-se o contraste entre ambas experiências no que se refere àinfraestrutura, manutenção e problematização do espaço em relação à proposta almejada. Nas duas experiências, apesar da importância que as crianças atribuemaos espaços externos,às brincadeiras e movimentos, ambos não adquirem a centralidade no trabalho pedagógico das escolas, seja pela falta de condições estruturais ou pela própria proposta pedagógica adotada.

De modo geral, considerando os diferentes contextos investigados, as análises mostraram o emprego de posturas adultocêntricas por parte das educadoras. Tais posturas foram reveladas nas imposições de brincadeiras, nas tentativas de regulação dos corpos, espaços e materiais disponíveis nas áreas externas. As chamadas brincadeiras livres, que quase sempre acontecem nessas áreas, parecem não contar com o investimento das educadoras, no sentido de adotarem uma postura mediadora entre as crianças, ou entre elas, os 


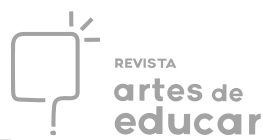

espaços e materiais disponíveis. Quando a intervenção acontece é marcada pela prevenção frente ao risco de acidentes, desencorajando muitas vezes as experiências das crianças.

\section{REFERENCIAS}

ANDRADE, R. C.A rotina da pré-escola na perspectiva das professoras, das crianças e de suas famílias. 2007. 301 f. Tese (Doutorado em Educação) - Faculdade de Educação, Universidade Federal do Ceará, Fortaleza, 2007.

ARAÚJO, V. C. A brincadeira na instituição de educação infantil em tempo integral:o que dizem as crianças? 2008. 138f. Dissertação (Mestrado em Educação) - Universidade Federal de Juiz de Fora, Juiz de Fora, 2008.

BRASIL, Ministério da Educação e do Desporto. Secretaria de Educação Básica. Parâmetros Básicos de Infraestrutura para instituições de Educação Infantil. Brasília, 2006.

CAMPOS de C., M. I. Pesquisas contextuais e seus desafios: uma contribuição a partir de investigações sobre arranjos espaciais em creches. Estudos de Psicologia, v. 8, no. 2,2003, p. 289-297.

CAMPOS, M. M.; CRUZ, S. H. V. Consulta sobre a qualidade na educação infantil:o que pensam os sujeitos deste direito. São Paulo: Cortez, 2006.

CORDAZZO, S. T. D. et alli. Metodologia Observacional para o estudo do brincar na escola. Avaliação Psicológica, v. 7, no. 3, 2008, p. 427-438.

FORNEIRO, L. I. A organização dos espaços na Educação Infantil. In: ZABALZA, M. A. Qualidade na Educação Infantil. Porto Alegre: Artmed, 1998.

GOBBI, M. A. Mundos na ponta do lápis: desenhos de crianças pequenas ou de como estranhar o familiar quando o assunto é criação infantil. Linhas Críticas, Brasília, DF, v. 20, no. 41, p. 147-165, jan/abr. 2014.

HADDAD, L.; HORN, M. da G. S. Criança quer mais do que espaço. Revista Educação. Edição especial: Educação Infantil 1. São Paulo: Editora Segmento, p. 42-59, set. 2011.

HORN, M. da G. S. Diagnóstico da utilização dos espaços físicos das unidades do PROINFANCIA, por amostra, apontando as principais distorções, subutilizações e dificuldades na organização dos espaços físicos conforme proposto no projeto. MEC, Brasília, 2013.

Sabores, Cores, sons, aromas: a organização dos espaços na Educação Infantil. Porto Alegre: Artmed, 2007.

KISHIMOTO, T. M. Brinquedos e materiais pedagógicosnas escolas infantis. Educação e Pesquisa, São Paulo, v. 27, n. 2, p. 229-245,jul./dez. 2001. 
KUHNEN, A.; RAYMUNDO, L.dos S.; GUIMARÃES, A. M. F.; SANTOS, G. F. dos. A linguagem do espaço físico na Educação Infantil. Barbarói. Santa Cruz do Sul, no. 35, ago/dez, 2011.

MARTINS, R.; GARANHANI, M. A organização do espaço na Educação Infantil:o que contam as crianças? Revista Diálogo Educacional. Paraná, V. 11, no. 32, 2011. p. 37- 56.

RICHTER, A. C.; VAZ, A. F. Momentos do parque em uma rotina de educação infantil: corpo, consumo, barbárie. Educação e Pesquisa. São Paulo, v. 36, n. 3, p. 673-684, set./dez. 2010.

SANTOS, C. O. dos. As concepções das crianças, professora e coordenadora pedagógica sobre o recreio como atividade da rotina em uma escola pública de Educação Infantil na cidade de Fortaleza. 2015. 197f. Dissertação (Mestrado em Educação). Faculdade de Educação, Universidade Federal do Ceará, Fortaleza, 2015.

SILVA, M. C. F. Do jardim de infância ao Centro de Actividades de Tempos Livres: representações das Crianças sobre o brincar. 2010. 187 f. Dissertação (Mestrado em Estudos da Criança) - Universidade do Minho, Braga, 2010.

SILVA, R. C.; ZOBERI, A.; SINTOBI,S. Quando os objetos dizem como brincar: organização de espaços e ambientes e a melhoria do brincar na UMEI São João. Relatório de Pesquisa. Belo Horizonte: CAPES/FAPEMIG, junho, 2016.

SILVEIRA, D. de B. A escola na visão das crianças. In: $27^{\mathrm{a}}$ Reunião Anual da ANPEd - GT 07, Caxambu/ MG, 2004.Disponível em: http://www.anped.org.br/reunioes/27/inicio.htm.

Acesso em: 25 mai. 2016.

TIRIBA, L. Diálogos entre a arquitetura e a pedagogia: educação e vivência do espaço.

Revista Virtual de Gestão de Iniciativas Sociais. UFRJ/TDS, no. 8, abril 2008. p. 37-43.

TRINCA, W. Formas de investigação clínica em psicologia: procedimento de desenhos estórias, procedimento de desenhos de família com estórias. São Paulo: Vetor, 1997.

\footnotetext{
iProfessor adjunto da Universidade Federal de Minas Gerais (UFMG). Brasil. Departamento de Métodos e Técnicas de Ensino. Faculdade de Educação. Doutor em Educação pela Universidade Federal de Minas Gerais.E-mail:rogex.correia@gmail.com. https://orcid.org/0000-0002-8662-9242

iiProfessora do Departamento de Educação da Universidade do Estado do Rio Grande do Norte (UERN). Faculdade de Educação. Brasil. Doutoranda em Educação pela Universidade Federal de Minas Gerais (UFMG). E-mail: celianeoliveira@ uern.br. https://orcid.org/0000-0002-2278-3267

${ }^{3}$ O Procedimento de Desenho-Estórias reúne e utiliza informações oriundas de técnicas gráficas e temáticas de modo a se constituir em nova e diferente abordagem da vida psíquica. Basicamente, é formado pela associação de expressivo-motores (entre os quais se inclui o desenho livre) e processos aperceptivos-dinâmicos (verbalizações temáticas). Dessa junção surge um instrumento individualizado, que se diferencia de outras técnicas de investigação. Ele consiste em cinco unidades de produção, que são realizadas pelo examinando, sendo cada qual composta por desenho livre, "inquérito" e título (TRINCA, 1997, p. 13).
} 
${ }^{4}$ Podem ser resumidas em quatro pontos: a forma de interação ou parceria das crianças durante o brincar (comportamento solitário, interação paralela, interação associativa); ao tipo de brincadeiras (brincadeira de fazde-conta, brincadeira construtiva, jogos de regra, Brincadeira proposta; Brincadeira turbulenta); a outras interações não caracterizadas como brincadeiras: atividade de conversa, agressão, exploração do ambiente; Por fim, buscamos identificar se tais interações ocorridas nos espaços havia ou não a mediação do adulto.

${ }^{5}$ Os nomes das crianças são fictícios. 